\title{
Does implementation of a diagnostic pathway for acute aortic syndrome including $D$-dimer increase the usage of $D$-dimer and computed tomography?
}

\author{
Robert Ohle ${ }^{1} \cdot$ Nicholas Fortino $^{1} \cdot$ Sarah $_{\text {Mclsaac }^{2}} \cdot$ Aaron Regis $^{3} \cdot$ Owen Montpellier $^{3} \cdot$ Mackenzie Ludgate $^{3}$. \\ Owudami Bolunde ${ }^{3}$. Cait Dmitriew ${ }^{3}$
}

Received: 18 June 2020 / Accepted: 2 February 2021 / Published online: 6 April 2021

(c) The Author(s), under exclusive licence to Canadian Association of Emergency Physicians (CAEP)/ Association Canadienne de Médecine d'Urgence (ACMU) 2021

\begin{abstract}
Introduction The Canadian clinical practice guidelines propose a novel diagnostic pathway incorporating a clinical decision tool and D-dimer to aid in risk stratifying patients for acute aortic syndrome. The objective of this study was to assess if implementation of a diagnostic pathway incorporating D-dimer would increase the usage of D-dimer and computed tomography $(\mathrm{CT})$ in a tertiary care emergency department.

Methods Prospective single centre before and after study-recruiting patients over a 6-week period from a tertiary care emergency department. Intervention: multi model implementation of a diagnostic pathway for acute aortic syndrome incorporating D-dimer. Outcome: proportion of patients receiving D-dimer testing/CT in the 2 weeks before and after implementation.

Results We included 982 patients (Female 55\%, Age mean 51.9, $N=492$ pre intervention and $N=490$ post intervention). The proportion that received a D-dimer test increased from 6.9 to $10.4 \%(p<0.051)$, while the number of CT aortas remained stable $(0.6 \%$ vs. $0.6 \% ; p=0.60)$. Documentation of pretest probability assessment increased from 1 to $3 \%,(p<0.009)$ following the intervention. In the post intervention cohort, the tool was applied correctly in all cases $(N=17)$.

Conclusion This single centre study found that a diagnostic pathway for acute aortic syndrome including D-dimer could be implemented without a significant increase in test ordering during this first 2 weeks after implementation. This study adds to the argument for use of D-dimer to help risk stratify patients for the diagnosis of acute aortic syndrome. Future studies are needed to confirm the diagnostic accuracy of this pathway and the long-term impact on resource utilization.
\end{abstract}

Keywords Acute aortic syndrome $\cdot$ D-dimer $\cdot$ Computed tomography

Robert Ohle

Robert.ohle@gmail.com

1 The Department of Emergency Medicine, Health Science North Research Institute, Northern Ontario School of Medicine, 41 Ramsey Lake Rd, Sudbury, ON P3E 5J1, Canada

2 Department of Critical Care, Department of Anaesthesia, Northern Ontario School of Medicine, Sudbury, ON, Canada

3 Department of Undergraduate Medicine, Northern Ontario School of Medicine, Sudbury, ON, Canada 


\section{Résumé}

Introduction Les guides de pratique clinique canadiens proposent une nouvelle voie de diagnostic intégrant un outil de décision clinique et du D-dimère pour aider à stratifier le risque chez les patients atteints du syndrome aortique aigu. L'objectif de cette étude était d'évaluer si la mise en place d'une voie diagnostique intégrant le dimère-D augmenterait l'utilisation du dimère-D et de la tomodensitométrie (TDM) dans un service d'urgence de soins tertiaires.

Méthodes Centre unique prospectif avant et après l'étude - recrutement de patients sur une période de 6 semaines à partir d'un service d'urgence de soins tertiaires. Intervention : mise en œuvre multi-modèle d'une voie diagnostique pour le syndrome aortique aigu intégrant le D-dimère. Résultat : Proportion de patients ayant subi un test des D-dimères/TDM dans les deux semaines précédant et suivant la mise en œuvre.

Résultats Nous avons inclus 982 patients (femmes $55 \%$, âge moyen $51,9, \mathrm{~N}=492$ avant l'intervention et $\mathrm{N}=490$ après l'intervention). La proportion de personnes ayant reçu un test D-dimère est passée de $6,9 \%$ à $10,4 \%(p<0,051)$, tandis que le nombre d'aortes CT est demeuré stable $(0,6 \%$ contre $0,6 \% ; \mathrm{p}=0,60)$. La documentation de l'évaluation de la probabilité avant le test est passée de $1 \%$ à $3 \%(\mathrm{p}<0,009)$ après l'intervention. Dans la cohorte post-intervention, l'outil a été appliqué correctement dans tous les cas $(\mathrm{n}=17)$.

Conclusion Cette étude menée auprès d'un seul centre a révélé qu'une voie diagnostique pour le syndrome aortique aigu, y compris le D-dimère, pourrait être mise en œuvre sans qu'il y ait une augmentation significative de l'ordre des tests au cours des deux premières semaines suivant la mise en œuvre. Cette étude renforce l'argument en faveur de l'utilisation du D-dimère pour aider à stratifier les risques des patients pour le diagnostic du syndrome aortique aigu. De futures études sont nécessaires pour confirmer la précision du diagnostic de cette voie et l'impact à long terme sur l'utilisation des ressources.

\section{Clinician's capsule}

\section{What is known about the topic?}

Canadian clinical practice guidelines suggest that D-dimer can be used for risk stratification of patients for acute aortic syndrome.

\section{What did this study ask?}

Does implementation of a diagnostic pathway for acute aortic syndrome including D-dimer increase the usage of D-dimer and computed tomography (CT)?

\section{What did this study find?}

There was a small (3.5\%) increase in D-dimer usage without an increase in CT ordering.

\section{Why does this study matter to clinicians?}

The addition of D-dimer to a diagnostic pathway for acute aortic syndrome may not increase resource utilization.

\section{Introduction}

Acute aortic syndrome is a time dependent aortic catastrophe. It is a clinical syndrome defined by three distinct diagnoses; acute aortic dissection, intramural hematoma and penetrating atherosclerotic ulcer. It is a rare but serious condition that should be considered in anyone presenting with acute chest pain to the emergency department [1]. Unlike more common diagnoses such as acute coronary syndrome and pulmonary embolism there is no widely used method of risk stratifying patients for this high-risk condition. This has led to a wide variation in investigation strategies and a high miss rate $[2,3]$.

The Canadian clinical practice guidelines propose a novel diagnostic pathway incorporating a clinical decision tool that uses signs, symptoms and the results of bedside testing to risk stratify patients into low, moderate or high pre-test probability. The decision tool suggests a utility for D-dimer in moderate risk patients, if negative no further investigation and if positive an expedited computed tomography (CT) should be performed. There is concern that implementation of D-dimer testing for acute aortic syndrome will result in an increased number of false positive tests and thus increased rates of CT due to the low specificity of D-dimer and low prevalence of acute aortic syndrome [4]. The second concern is indication creep, with D-dimer being applied to patients who previously would not have been considered at risk for acute aortic syndrome.

Prior to the publication of these practice guidelines we developed a diagnostic pathway based on expert consensus that incorporated a pre-test probability assessment and the use of D-dimer. Our primary objective was to assess whether resource utilization (D-dimer or CT ordered) increased following the implementation of a diagnostic pathway for acute aortic syndrome that incorporates D-dimer. Our secondary objective was to assess the effectiveness of a simple implementation strategy for the diagnostic pathway by evaluating frequency and adherence to tool use. 


\section{Methods}

This was a before and after study. Data were prospectively collected 2 weeks prior to the intervention, a 2-week period was allowed for the intervention and then data for 2 weeks post intervention were collected. We included adults greater than 18 years with presenting complaints associated with acute aortic syndrome (chest, back, abdominal and flank pain, cerebrovascular accident possible with pain, neurological deficit with pain, syncope with pain or altered level of consciousness with pain). These were based on the Canadian emergency department information system (CEDIS) presenting complaints that are indexed in our electronic health records. We excluded patients with pain greater than 14 days, trauma within $24 \mathrm{~h}$ of pain onset, pregnancy, cocaine use within 24 hrs or known acute aortic syndrome.

\section{Study intervention}

The diagnostic pathway included a clinical decision aid risk stratifying patients into low (no investigation), moderate (D-dimer) or high probability (CT) (Box 1). It is important to note that this was an expert consensus decision aid that was developed locally and is different to the decision aid published in the Canadian clinical practice guidelines for the diagnosis of acute aortic syndrome. It was actively implemented over a 2 -week period. Educational initiatives included a 20-min teaching session at a departmental meeting to review the evidence and clinical application of the pathway and clinical decision aid, including the use of D-dimer as part of this pathway. We also placed posters of the diagnostic pathway in the emergency department. All practicing physicians within the department were also sent a 5 min video tutorial. Lastly, an online tool calculator was made available to physicians $[5,6]$.

\section{Box 1}

The diagnostic pathway for acute aortic syndrome (AAS) including a pre-test probability assessment tool together with suggestions for investigation depending on the risk level of the patient.

\section{Step one}

RAPID assessment for AAS-Move to step two if any of the following

Risk factors-connective tissue disease, aortic aneurysm, family history of aortic disease, bicuspid aortic valve

Alternative diagnosis in the differential that mimics acute aortic dissection- ACS, PE, Stroke

Physical exam—hypotension, pulse deficit, new murmur

Impression—clinical suspicion for AAS

\begin{tabular}{|c|c|c|c|}
\hline \multicolumn{4}{|c|}{$\begin{array}{l}\text { Discomfort-HIGH RISK pain-Thunderclap, tearing, ripping } \\
\text { LOW RISK pain-migrating, pleuritic, severe, pain + patient } \\
\text { reported neuro deficit }\end{array}$} \\
\hline \multicolumn{4}{|l|}{ Step two } \\
\hline Risk factors & 1 or more risk factor & 1 & \\
\hline \multirow[t]{3}{*}{ Impression } & Slightly or no suspicion & 1 & 1 or 2 low-risk pain \\
\hline & Moderately suspicious & 2 & $\begin{array}{c}>2 \text { low-risk pain OR } \\
\text { any high-risk pain }\end{array}$ \\
\hline & Highly suspicious & 3 & $\begin{array}{l}\text { Multiple high-risk } \\
\text { pain features }\end{array}$ \\
\hline Physical exam & $\begin{array}{l}\text { Hypotension and/or } \\
\text { pulse deficit }\end{array}$ & 2 & \\
\hline
\end{tabular}

\section{Data collection}

At our centre, we use standardized pre-printed charts that combine circling relevant information with space for free text notes. We embedded the tool and reviewed all charts related to presenting complaints associated with acute aortic syndrome (chest, back, abdominal and flank pain, cerebrovascular accident possible, neurological deficit, syncope or altered level of consciousness). An example of the tool embedded in one of the charts can be found in Supplemental Appendix 1.

Electronic records were screened to collect variables for each of the tool criteria and investigations. D-dimer was extracted from the laboratory results section of the electronic records and computed tomography was extracted from the imaging section. When variables were not documented in a patient's chart, we assumed they were negative, adopting the approach used by IRAD (international registry for acute aortic dissection), the largest international database for acute aortic syndrome [7]. Clinical suspicion for an alternative diagnosis was extrapolated from discharge diagnosis. When the physician's discharge diagnosis was a symptom (i.e., chest pain) followed by not yet diagnosed or unspecified, this was coded as alternative diagnosis "unsure" on the tool. Most likely diagnosis was coded as acute aortic syndrome if a CT aorta was ordered to rule out acute aortic syndrome.

Documentation of pre-test probability assessment pre intervention was coded as yes if mention of acute aortic syndrome in the differential and/or described as either low, moderate, high or a variation of those terms. Post intervention documentation of pre-test probability was coded as yes when the decision aid was reported.

Adherence of pathway use was assessed in the post-intervention group by comparing the score (calculated from the 
Fig. 1 Flow diagram of included patients and outcomes

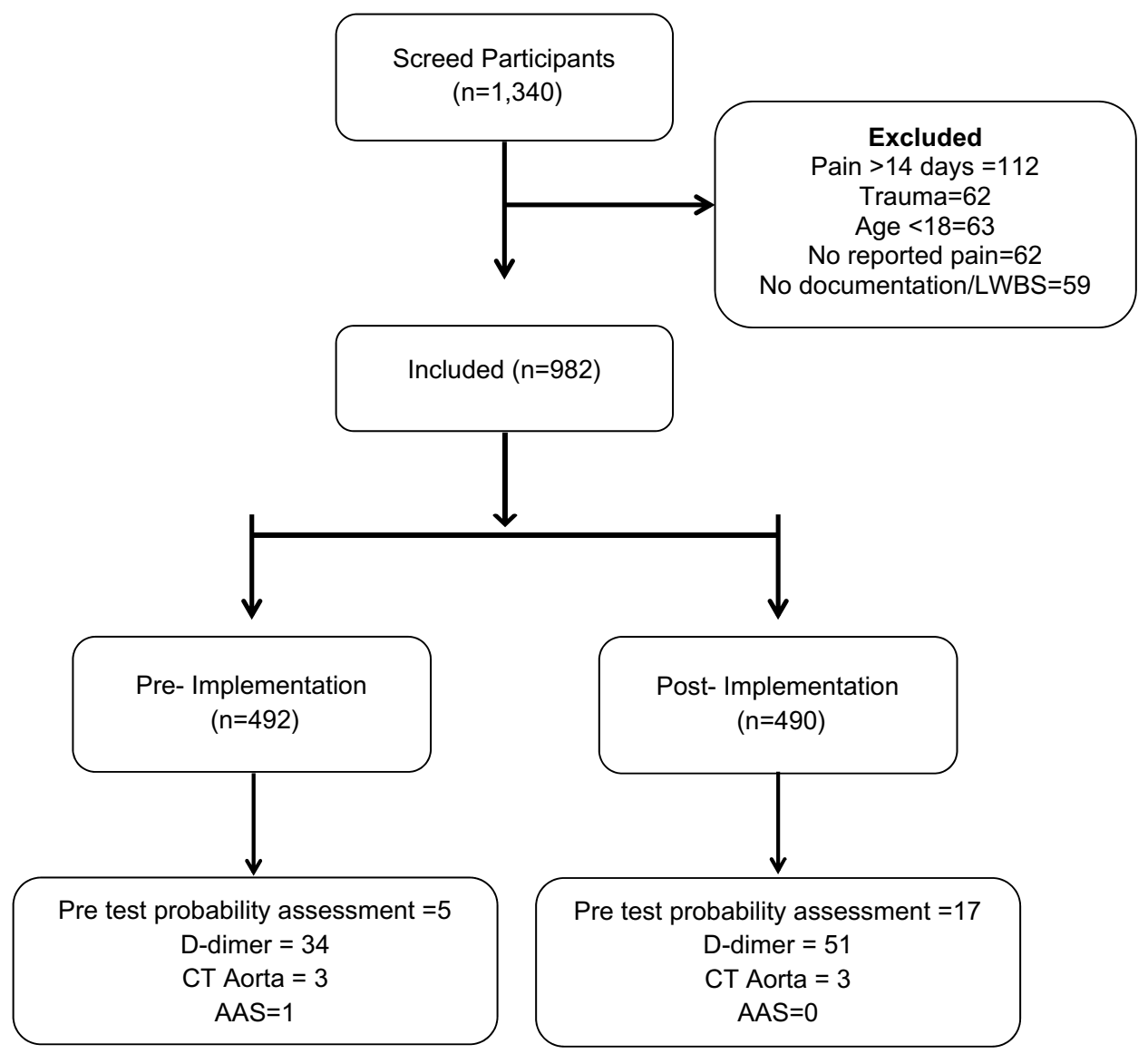

retrospective chart review) with the diagnostic tests ordered (D-dimer, CT aorta or no further investigation).

Institutional ethics review board approved this study.

\section{Data analysis}

We reported means, medians and proportions where appropriate. When comparing pre and post implementation. Continuous variables were compared using the two-sided Student $t$ test for normal distributions and the Mann-Whitney $U$ test for non-normal distributions. The categorical variables were compared using the Chi-square test or Fisher's exact test, as appropriate. A sample size of 756 patients was calculated based on an $80 \%$ power and confidence interval of $95 \%$ to detect an increase of $5 \%$ of D-dimer ordered. Prior to implementation, we estimated from health records review that $5 \%$ of patients presenting with a triage complaint of chest pain received D-dimer testing. The $95 \%$ confidence interval around that proportion was $0.03-0.08$. Therefore we chose greater than $5 \%$ change to reflect a true increase.

\section{Results}

We screened 1340 patients, 656 before and 684 after implementation, including 1 acute aortic syndrome. We included 982 patients (female 55\%, mean age 51.9, SD 20.3, $N=492$ pre intervention and $N=490$ post intervention). The most common diagnoses in both groups were similar, the three most common being; "chest pain not otherwise specified", "abdominal pain" and "musculoskeletal chest wall pain".

The proportion that received a D-dimer test increased from 6.9 to $10.4 \%(p<0.051)$, while the number of $\mathrm{CT}$ aortas remained stable $(0.6 \%$ vs. $0.6 \% ; p=0.60)$. Documentation of pretest probability assessment increased from 1 to $3 \%,(p<0.009)$ following the intervention (Fig. 1.). In the post intervention cohort, the tool was applied correctly in all patients in whom it was used $(N=17)$ (Table 1$)$. 
Table 1 Frequency of test ordering and high-risk features for acute aortic syndrome pre and post implementation of a diagnostic pathway for acute aortic syndrome female $55 \%$, mean age 51.9, SD 20.3

\begin{tabular}{|c|c|c|}
\hline \multirow[t]{2}{*}{ Base line variables } & \multicolumn{2}{|l|}{$\mathrm{N}(\%)$} \\
\hline & Pre $(N=492)$ & Post $(N=490)$ \\
\hline Age (mean (SD)) & $53.1(19.8)$ & $52.4(20.8)$ \\
\hline Female & $261(53)$ & $285(58)$ \\
\hline \multicolumn{3}{|l|}{ Most common final diagnosis } \\
\hline Chest pain unspecified & $83(16.8)$ & 87 (17.7) \\
\hline Abdominal pain unspecified & $72(14.6)$ & $74(15.1)$ \\
\hline Musculoskeletal chest wall pain & $54(11)$ & $52(10.6)$ \\
\hline \multicolumn{3}{|l|}{ Risk factors } \\
\hline Family history & 0 & $1(0.2)$ \\
\hline Aortic manipulation & 0 & 0 \\
\hline Aortic valve disease & $3(0.61)$ & $3(0.61)$ \\
\hline Known aortic aneurysm & $2(0.41)$ & $2(0.41)$ \\
\hline Connective tissue disease & $1(0.2)$ & 0 \\
\hline No risk factors & $486(98.8)$ & $484(98.8)$ \\
\hline \multicolumn{3}{|l|}{ Pain } \\
\hline Abrupt-onset pain & $70(14.22)$ & $60(12.24)$ \\
\hline Tearing/ripping & 0 & $2(0.41)$ \\
\hline Migrating/radiating pain & $79(16.1)$ & $61(12.24)$ \\
\hline Severe & $121(24.6)$ & $117(23.9)$ \\
\hline No high risk pain & $222(45.1)$ & $250(51)$ \\
\hline \multicolumn{3}{|l|}{ Physical exam } \\
\hline Hypotension & $6(1.22)$ & $8(1.63)$ \\
\hline New murmur & 0 & $5(1.02)$ \\
\hline Pulse deficit & $1(0.2)$ & 0 \\
\hline Focal neurological deficit & $8(1.63)$ & $10(2.04)$ \\
\hline No high risk physical exam findings & $477(97)$ & $467(95.3)$ \\
\hline \multicolumn{3}{|l|}{ Impression } \\
\hline Clinical suspicion for an alternative diagnosis & $251(51)$ & $251(51.2)$ \\
\hline Unsure & $238(48.4)$ & $236(48.2)$ \\
\hline Acute aortic syndrome most likely diagnosis & $3(0.61)$ & $3(0.61)$ \\
\hline \multicolumn{3}{|l|}{ Outcome variables } \\
\hline D-dimer & $34(6.9)$ & $51(10.4)$ \\
\hline Computed tomography aorta & $3(0.6)$ & $3(0.6)$ \\
\hline Documentation of pre-test probability & $5(1)$ & $17(3.5)$ \\
\hline
\end{tabular}

\section{Discussion}

\section{Interpretation}

This single centre study found that a diagnostic pathway for acute aortic syndrome could be implemented without a significant increase in test ordering during this first 2 weeks after implementation.

\section{Previous studies}

The guidance from national guidelines varies with respect to recommendations for D-dimer use in risk stratification of acute aortic syndrome [8-10]. The first prospective trial (ADVISED trial) validating its use for the risk stratification of patients with a clinical suspicion for acute aortic syndrome was performed in 2019 [11]. However, the impact of this or any diagnostic pathway on rates of D-dimer and CT ordering has not yet been assessed.

\section{Clinical and research implications}

Our study is the first to study the effect on D-dimer ordering and consequently $\mathrm{CT}$ ordering, when it is endorsed as part of a diagnostic algorithm. While there was a small increase in D-dimer ordering following the intervention, ordering of CT aorta remained unchanged. Our results support the feasibility of a larger prospective implementation of the diagnostic pathway to establish its ability to successfully risk stratify patients for acute aortic syndrome. 
While there was a significant increase in documentation of pre-test probability for acute aortic syndrome post implementation, overall uptake was low. This may be due to clinicians appropriately not applying in cases with a clear alternative diagnosis. However, barriers and facilitators to use of the clinical decision tool should be explored in future studies, to inform a maximally effective approach to implementation. Our intervention relied largely on education. According to the hierarchy of effectiveness of interventions this is a low leverage/least effective intervention. Moderately effective interventions such as reminders/checklists or standardization of ordering were not employed. Additionally high leverage interventions such as forcing functions were not employed. A forcing function at time of ordering of a computed tomography may increase the effectiveness of the change strategy [12].

\section{Strengths and limitations}

This before and after study did not have a control group; therefore, we do not know if the small increase in D-dimer usage is a reflection of an overall trend independent of the intervention. We did not employ a time series or regression analysis that is to be used for before-after studies. The lack of increase in resource utilization may be a reflection of uptake by only a small subset of physicians. The short post intervention period does not allow for any comment on change in practice over a longer period of time.

We defaulted variables to absent if not documented. The IRAD (international registry for acute aortic dissection) database, the largest international database for acute aortic syndrome, routinely collects data retrospectively and defaults values to negative if they are not documented.

\section{Conclusions}

This single centre study found that a diagnostic pathway for acute aortic syndrome including D-dimer could be implemented without a significant increase in test ordering during this first 2 weeks after implementation. This is the first study to explore the impact of using D-dimer together with a tool to assess pre-test probability. Future studies are needed to explore the long-term impact on resource utilization and the accuracy of D-dimer in ruling out acute aortic syndrome.

Supplementary Information The online version contains supplementary material available at https://doi.org/10.1007/s43678-021-00096-w.
Author contributions RO was responsible for study design, analysis and manuscript preparation. NF, OM, $\mathrm{AR}$ and $\mathrm{OB}$ were responsible for data extraction. $\mathrm{CD}$ was responsible for manuscript editing, formatting and co-writing. RO acts as guarantor for accuracy and integrity of the manuscript.

\section{Compliance with ethical standards}

Conflict of interest The authors declare that they have no conflict of interest.

\section{References}

1. Klompas M. Does this patient have an acute thoracic aortic dissection? JAMA J Am Med Assoc. 2002;287(17):2262-72.

2. Ohle R, Anjum O, Bleeker H, Wells G, Perry JJ. Variation in emergency department use of computed tomography for investigation of acute aortic dissection. Emerg Radiol. 2018;2018:1-6.

3. Ohle R, Um J, Anjum O, Bleeker H, Luo L, Wells G, Perry JJ. High risk clinical features for acute aortic dissection: a case-control study. Acad Emerg Med. 2018;25(4):378-87.

4. Watanabe H, Horita N, Shibata Y, Minegishi S, Ota E, Kaneko T. Diagnostic test accuracy of D-dimer for acute aortic syndrome: systematic review and meta-analysis of 22 studies with 5000 subjects. Sci Rep. 2016;6:26893.

5. Grimshaw J, Eccles M, Tetroe J. Implementing clinical guidelines: current evidence and future implications. J Cont Edu Health Prof. 2004;24(S1):S31-7.

6. Oxman AD, Thomson MA, Davis DA, Haynes RB. No magic bullets: a systematic review of 102 trials of interventions to improve professional practice. CMAJ Can Med Assoc J. 1995;153(10): 1423.

7. Hagan PG, Nienaber CA, Isselbacher EM, Bruckman D, Karavite DJ, Russman PL, Evangelista A, Fattori R, Suzuki T, Oh JK. The International registry of acute aortic dissection (IRAD): new insights into an old disease. JAMA. 2000;283(7):897-903.

8. Hiratzka LF, Bakris GL, Beckman JA, Bersin RM, Carr VF, Casey DE, Eagle KA, Hermann LK, Isselbacher EM, Kazerooni EA. 2010 ACCF/AHA/AATS/ACR/ASA/SCA/SCAI/SIR/STS/SVM guidelines for the diagnosis and management of patients with thoracic aortic disease. J Am Coll Cardiol. 2010;55(14):e27-129.

9. Erbel R, Aboyans V, Boileau C, Bossone E, Di Bartolomeo R, Eggebrecht H, Evangelista A, Falk V, Frank H, Gaemperli O. 2014 ESC Guidelines on the diagnosis and treatment of aortic diseases. Eur Heart J. 2014;35(41):2873-926.

10. Diercks DB, Promes SB, Schuur JD, Shah K, Valente JH, Cantrill SV. Clinical policy: critical issues in the evaluation and management of adult patients with suspected acute nontraumatic thoracic aortic dissection. Ann Emerg Med. 2015;65(1):32-42.e12.

11. Nazerian P, Mueller C, Soeiro AD, Leidel BA, Salvadeo SA, Giachino F, Vanni S, Grimm K, Oliveira MT Jr, Pivetta E, Lupia E. Diagnostic accuracy of the aortic dissection detection risk score plus D-dimer for acute aortic syndromes: the ADvISED Prospective Multicenter Study. Circulation. 2018;137(3):250-8.

12. Grzywacz JG, Fuqua J. The social ecology of health: Leverage points and linkages. Behav Med. 2000;26(3):101-15. 